Article

\title{
Health professional workforce education in the Asia Pacific
}

\author{
Jessica Lees, Gillian Webb, Frances Coulston, Aidan Smart, Louisa Remedios \\ University of Melbourne, Australia
}

Significance for public health

The Global Learning Partnership model aims to contribute to the capacity building of a health workforce that is capable of working effectively in cross cultural and interprofessional health care teams. A shared public health focused global placement has the potential to catalyse collaborative relationships between educational institutions in the Asia Pacific region.

\section{Abstract}

Objective. To design and implement an international and interprofessional Global Learning Partnership Model, which involves shared learning between academics and students from Universitas 21 network with other universities with United Nations Millennium Development Goal needs.

Design. Two literature reviews were conducted to inform ethical aspects and curriculum design of the GLP model. Feedback from conference presentations and consultation with experts in education and public health has been incorporated to inform the current iteration of the GLP model.

Intervention. The pilot group of 25 students from U21 universities and Kathmandu University, representing six health disciplines will meet in Nepal in April 2016 for a shared learning experience, including a one week university based workshop and three week community based experience.

Outcome measures. A multi-phase, mixed method design was selected for the evaluation of the GLP model, utilising a combination of focus groups and questionnaires to evaluate the efficacy of the placement through student experience and learning outcomes in cultural competency, UN SDG knowledge, community engagement and health promotion skills.

Results. The literature review demonstrated that cultural awareness and cultural knowledge were improved through participation in cultural immersion programs that incorporated preparatory workshops and clinical experiences. Data will be gathered in April 2006 and the results of the evaluation will be published in the future.

Conclusions. The GLP model proposes a project around the fundamental concept of engagement and sharing between students and academics across universities and cultural contexts to build capacity through education, while capitalising on strengths of existing global health placements. Further the inclusion of host-country students and academics in this learning exchange will promote the establishment of an international and interprofessional network for ongoing health promotion.

\section{Introduction}

Health outcomes in many countries in the Asia Pacific region are some of the worst in the world. ${ }^{1}$ Physical disability through chronic diseases, ageing populations, and trauma contributes considerably to high morbidity rates and have significant economic costs to all communities. ${ }^{1}$ The health workforce has a key role to play in the prevention and rehabilitation of people with disabilities.

There is a strong focus on building capacity of local workforces through educational opportunities particularly directed at sharing knowledge and resources between universities and health facilities across borders. The Sustainable Development Goals (SDG) recently launched by the United Nations emphasise the need for strong partnerships for a positive development trajectory. ${ }^{2}$

In 2006 the Universitas 21 (U21) Health Science group passed a resolution to establish a U21 United Nations Millennium Development Goals (UNMDG) Interest Group. This Interest Group is connected with the United Nations Department of Economic and Social Affairs to strategize for the implementation of a Millennium Development Goals action plan for U21. With the recent launch of the United Nations Sustainable Development Goals the importance of relationship building is highlighted even further. The U21 Interest Group strives to create a unique experience and provide resources for students that will prepare them for life and work across borders and cultures, as is required to achieve global health equity. The group recognises the importance of the SDGs as an international development agenda and is focused on ensuring that this critical agenda is included in the curriculum of health professionals in a meaningful way.

This paper focuses on one particular initiative with a primary agenda to engage an interdisciplinary and international group of students and academics in a collaborative learning experience: this is the Global Learning Partnership (GLP). Included within this project is a model of experiential learning that seeks to contribute to the learning of health professional students around the aspirations of the SDGs. The development of collaborative partnerships between academic institutions is a key goal of the GLP. Furthermore this paper also explores a number of ethical considerations relating to the development of international partnerships and student field experience.

\section{The Global Learning Partnership}

The purpose of the following section of the paper is threefold: to present the Global Learning Partnership (GLP) model, a new framework for global student placements; to describe the evidence and process for development of the model; and to describe the planned evaluation for the pilot implementation project.

The goal of the GLP model is to create the architecture for a partnership strategy to enable health science students and academics 
from various universities to actively learn from and with each other. The primary objective of this collaboration is to enhance global health education and develop skills that support action towards achieving the United Nations development goal targets and beyond. The GLP model was developed and refined via two literature reviews, expert opinion, and multiple presentations to peer and professional audiences.

The process of developing the GLP model began in 2011, through a group of research intensive Universities known as Universitas 21. The Universitas 21 United Nation's Millennium Development Goal (U21 UNMDG) Student Committee proposed that developing a shared UNMDG project would strengthen the committee's activity; it would also be in alignment with the governing U21 UNMDG Interest Group's mandate to contribute to the achievement of the Millennium Development Goals through education and partnerships. This shared UNMDG project was initially proposed at the annual U21 Health Science Group (HSG) Conference 2011 in Seoul, Korea, where it was decided to partner with a university in a country with UNMDG gaps in order to gain insight, and share resources and learning activities for mutual benefit. Initial feedback from the steering committee and extensive consultation with faculty in Nepal led to the decision to begin a four-week pilot project at Kathmandu University. To support this pilot project, it was clear that establishment of a rigorous framework and model supported by a review of the literature and evaluation tools, was paramount.

\section{The literature review informing the Global Learning Partnership}

From early in development it was recognized that the Global Learning Partnership model provided a unique opportunity to incorporate and evaluate elements of cultural immersion and interprofessional education. It was identified that further exploration of interprofessional education and international field placement programs were required to inform the development and evaluation of the GLP model. Two literature reviews were conducted to inform and refine the ethical and logistical aspects of the GLP model; one review focused on the development of cultural awareness and cultural knowledge; and one on interprofessional education and collaborative practice. The search was lim-

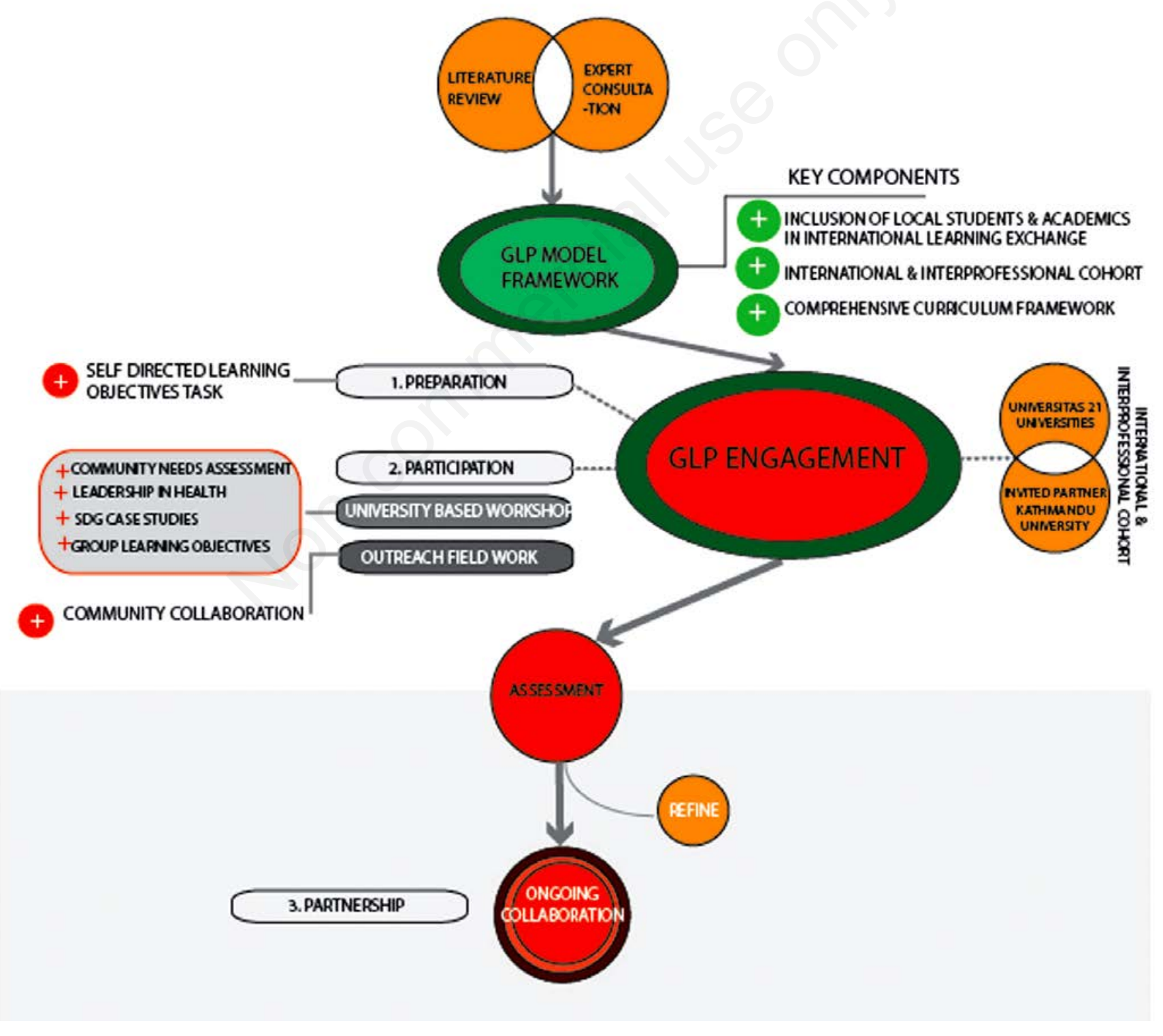

Figure 1. The Global Learning Partnership model. 
ited to empirical studies published from January 2003 to September 2013 and included undergraduate medical or healthcare student populations. Both reviews were conducted on the MEDLINE, ERIC and CINAHL databases. The first literature review extracted eight articles, which explored the efficacy of international field placements on developing elements of cultural competence in medical and health science students. The second review extracted nine articles, examining common elements of education programs and collaborative projects designed to facilitate interprofessional learning in students of medicine and allied health sciences. Findings from the literature review informed the GLP model in numerous ways. The literature review demonstrated that cultural competence, particularly cultural awareness and cultural knowledge is improved through participation in cultural immersion programs that incorporated preparatory workshops and a combination of clinical and homestay experiences. ${ }^{3-5}$ Furthermore, interprofessional learning is most commonly facilitated through problem-based learning sessions which improve students' awareness and understanding of different health professions . Students reportedly gain an increased understanding of their role in patients' care, as well as strengthening interprofessional communication through development of interprofessional relationships and shared learning experiences. ${ }^{6,7}$ Thus, these elements have been incorporated into the Global Learning Partnership model design.

\section{Global Learning Partnership design}

The design of the GLP model (Figure 1) is built around the fundamental concept of engagement and sharing between students and academics across universities and cultural contexts to build capacity through education. Whilst capitalising on strengths of existing global health placements, this approach is unique in focusing on the inclusion of host-country students and academics as a primary source of knowledge on local culture and local health needs. The GLP model will be piloted in May 2016, when U21 universities will partner with Kathmandu University in Nepal, which has been chosen by the UNMDG Interest Group as being located in a country with UNMDG gains to be made. Implementation of the GLP model in this context will catalyse the development of a relationship within the network of international universities via three phases: a preparatory phase, a participation phase and an ongoing partnership phase.

The preparation phase of the GLP model includes self-directed learning tasks centred on the creation of individual learning objectives and cultural awareness exercises. Individuals will be requested to reflect on and develop personal goals for the placement. This prior introspection will position the students as active learners, facilitating information acquisition that is shaped by values meaningful to the student and so provide more meaningful learning experiences.

Individual learning objectives will be based on three guiding influences: i) Universitas 21 and UNMDG Interest Group values; ii) desired student attributes and objectives as defined by respective universities and courses; and iii) personal goals.

Research suggests that self-directed learning is an educational strategy that will help produce healthcare clinicians who are prepared for lifelong learning and who will be equipped with the skills required to meet the changing needs of the community. ${ }^{8}$

The process of developing one's own learning objectives allows the individual to identify gaps in his or her knowledge; it may also enhance the encoding and retention of new information gained. ${ }^{9}$ A key concept discussed in constructivist learning theory is that ultimately the goals of the learner will be central in what is learned. ${ }^{10}$ Participants will also be provided with learning resources regarding Nepalese history, culture and customs, and will be required to complete a cultural competency exercise and questionnaire.

The participation phase is a four-week shared placement experience, which aims to provide a deep learning experience for the participants, as well as to catalyse an ongoing relationship between international partner universities. The GLP model proposes that one-week of university-based activities be held to develop meaningful foundations for the time spent working and learning together in the community placement. This time will allow academics and students to establish collegiate relationships with each other, while learning more about each other's learning objectives and the relevant theory and skills prior to the community placement. The key principle underpinning the inclusion of this element in the GLP is that knowledge evolves through social negotiation and through the evaluation of the viability of individual understandings. ${ }^{10}$

The $2^{\text {nd }}$ to $4^{\text {th }}$ week will involve the community placement, which will include a health needs analysis and the implementation of health promotion project that meets the communities needs. To give the placement substantive outcomes, the GLP model includes a framework around the placement to facilitate the learning experience (Table 1).

As outlined in the table above, the curriculum in the first week will be centred on university-based activities to develop meaningful foundations for practical work in Weeks 2-4. One of the key activities will be to develop a group set of learning objectives derived from the culmination of individual learning goals (as described above). The development of a cooperative set of learning objectives is believed to be beneficial on both an individual and group level. Since understanding is an individual construct, these understandings may be explored by testing the degree to which individuals learning objectives are compatible with those developed by others in the group. Cognitive conflict provides a strong stimulus and organiser for learning and this opportunity to negotiate personal and group learning goals will promote goal awareness for the students. ${ }^{10}$

Finally, the partnership phase represents an ongoing collaboration between the partner universities and their students and academics. One objective of this program is that the interaction in Nepal, combined with the student engagement, will create avenues for academics to have continuing and growing relationships. It is envisioned that these linkages will create the opportunity for the sharing of resources such as curriculum material, and facilitate the potential for collaborative research. The establishment of these academic networks may also facilitate staff exchange opportunities and so further facilitate the improvement of healthcare education in the global context.

Multi-stakeholder partnerships such as the one proposed by the Global Learning Partnership are being increasingly recognized as development game-changers and for fostering a drive for measurable outcomes. These partnerships have been highlighted in The Report of the High-Level Panel of Eminent Persons on the Post-2015 Development Agenda as a key focus for eradicating poverty. ${ }^{11}$ The pilot

Table 1. Outline of structure for four week engagement.

\section{Week 1: University-based learning}

Development of group learning objectives;

Activities responsive to collaborative group learning objectives; and Interprofessional case-base learning group activities U21 UN MDG/SDG case studies.

\section{Week 2-4: Team based field/clinical work}

Outreach clinical visit to rural location team- Interprofessional group of international partners on site; Link in with existing outreach clinics currently conducted by Kathmandu University; and Potential to conduct a needs assessment and team based community action plan. 
project, which will be held at Kathmandu University in 2016, also presents an opportunity for evaluation of the GLP model. The proposed evaluation plan of the GLP model is outlined in the next section.

\section{Evaluation of the Global Learning Partnership}

A multi-phase mixed method design is proposed over a three-year period permitting multiple insights into the outcomes, effectiveness and sustainability of the GLP model. Mixed methods evaluation encourages the use of multiple worldviews and paradigms and combines inductive and deductive approaches. The underlying philosophical assumptions of this mixed methods evaluation comes from a pragmatic paradigm, that is, a shared belief system that influences the kinds of knowledge researchers seek and how they interpret the evidence they collect. ${ }^{12}$ The qualitative evaluation will specifically collect data on the richness and complexity of the participants' experience, while the quantitative data will focus on the outcomes captured through questionnaire analysis.

The qualitative data will be collected using semi-structured interviews of students and academics seeking a holistic, in-depth picture of participant experiences. The sample size for the pilot of this model is 25 students and it is recognised that evaluation of a small sample size qualitatively limits generalisability, and evaluator interpretation during coding may create significant bias. However, qualitative methods have been proposed as the preferred method in order to become better informed in effective interprofessional learning strategies and have been used to study other clinical education models. ${ }^{13-15}$

The quantitative data will be collected from the student completion of three questionnaires: one focussed on cultural competency, one on interprofessional attributes, and the third on knowledge and application of UN SDGs. The findings of these questionnaires will provide a general evaluative overview by allowing understanding of the relationship among variables and by quantifying outcomes. The findings from the qualitative data will assist in refining and explaining the results from the quantitative data by exploring participant's views in more depth, mapping the complexity of the situation and conveying multiple perspectives of participants. In addition, the evaluation will explore if the two types of data show similar results or not and why, adding to the validity of the results. ${ }^{12}$ In this multi-phase design, there will be several evaluations conducted over time, which are visualised in Figure 2. Phase 1 will take place in May 2016 in Kathmandu, and phases 2 and 3 in 2017 and 2018 respectively. The types of data collected in each phase will be the qualitative methods mentioned above; semi-structured interviews, and weekly e-journals; and the three quantitative assessments, which will be administered at baseline, project completion and at the 12- and 24-month follow-ups.

The qualitative data will be analysed using thematic analysis, while descriptive statistics will be used the Questionnaire data. Conducting a thematic analysis of the qualitative data helps to draw out nuances and variations in experience that may not be discernable by the more blunt quantitative instruments. ${ }^{16}$

\section{Ethical considerations}

The Global Learning Partnership model espouses an equal share international partnership between academic institutions. This model and the resulting partnership will create opportunity for U21 students and academics to interact with students and academics from other universities in the region, including an invited university in a country with identified UN SDG needs. Face-to-face interactions through global health placements have the potential to be an effective means to facilitate and catalyse the development of this ongoing relationship.

\section{Paternalism versus partnership}

A critique commonly levelled at placements in developing countries is that paternalistic attitudes are promoted and that the main beneficiaries of the placement are the visiting students rather than the host universities or communities. ${ }^{17}$ The risk is that this model is bureaucratically paternalistic in that it purports to tell the partner university what is good practice and what is a good project design. Extensive consultation with the invited partner, Kathmandu University, has been undertaken to ensure that this risk is minimised.

The ethical considerations posed by this project are significant as the increasing demand for international health experiences prompts a call for universities to reassess their priorities to ensure that these placements involve appropriate actions and framework to contribute to reducing the global burden of disease. ${ }^{18,19}$ This ethical quandary is frequently present for organisational practices, and is not isolated to academic institutions, with both development ethics and global health ethics receiving increasing attention to establish justification for potentially paternalistic interventions that may conflict with autonomy. ${ }^{17}$ This has been in environments with a disparity of conditions and consequentially in power, such as those surrounding academic global health partnerships, and so it is essential that clear and mutually beneficial objectives be established from the onset. ${ }^{18}$

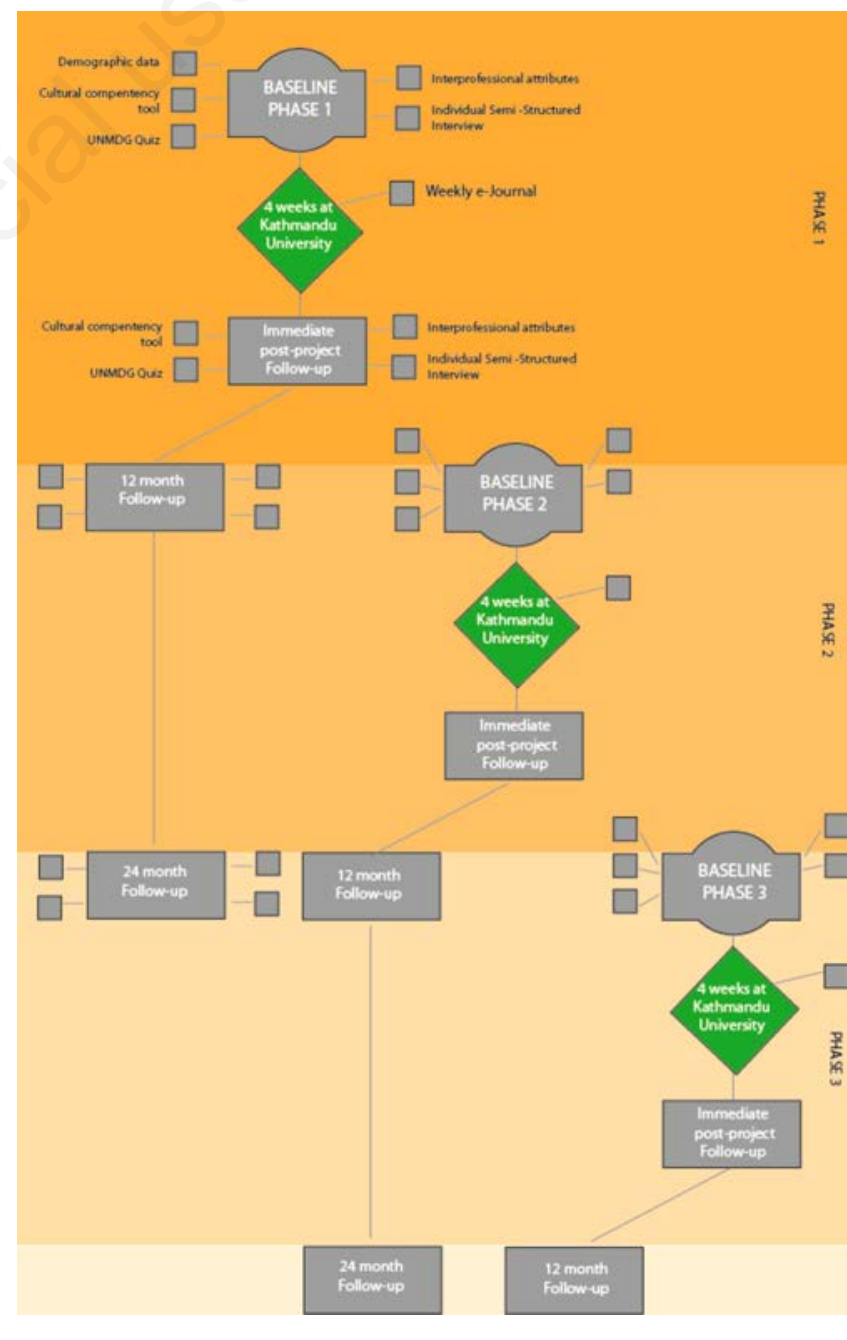

Figure 2. Proposed multi-phase mixed methods evaluation. 
The overarching principle of the model design is founded on the belief that Kathmandu University, as an academic institution in a developing country, would be able to contribute experiential development knowledge, as well as benefit from a partnership with Universitas 21 . This idea may be considered to be paternalistic as its guided by the belief that resources and curriculum held by Universitas 21 would be useful to Kathmandu and consequentially that sharing of these resources would contribute to capacity building of local workforce. Contesting this position, the GLP model seeks to explicitly learn from the expertise of the academic staff and students from Kathmandu University and seek genuine collaboration between the academics from the involved universities. The ethical dilemma presented by the GLP project has a strong history of discussion in philosophical and bioethics literature, particularly in the context of government policy. ${ }^{20}$

\section{Resource allocation}

Allocation of resources is an important ethical consideration, and in the development of a project proposal such as this, questions must also be raised that if the fundamental goal is to make a contribution towards resolving health disparities, are costly trips overseas the most effective use of funds? ${ }^{21,22}$ Global health placements often occur in resourcepoor environments and the constraints of these settings need to be considered. The universities sending students must be mindful of the resource burdens that their hosts may incur in order to receive students and academics. Visitors must also be aware of minimising their resource consumption. ${ }^{18}$

The proposers of this project must consider if allocation of resources to such an endeavour in this setting will ultimately lead to optimisation of the outcomes. ${ }^{17,22,23}$ In addition, it needs to be ensured that the allocation of funds is going to achieve the best outcome for the partner country's population through health workforce capacity building.

\section{Mutual benefit}

Scrutiny is required to ensure that there is not an unfair distribution of benefits. Visiting students undoubtedly stand to benefit from their experience. Studies exploring the impact of such global health experiences demonstrate numerous benefits, including increased knowledge, changes in attitudes, and enhanced medical skills. ${ }^{24,25}$ However, most students from visiting developed countries will practice in their own countries and therefore the benefits gained from global health experience will be transferred to patients in the developed world. Exploitation is a key and unacceptable risk if a burden of harm is placed on the population in the developing country as the students learn their skills in this context so patients in developed nations gain the most benefit. ${ }^{19}$ This is acceptable only if students in the host country make equal gains, and contribute to the health outcomes of patients and communities in the host country.

Consideration must be given to the risk-benefit ratio as although benefits such as increased medical access in the host country and a positive learning experience for the partner university's students are acquired, there are also related risks. Concerns such as cultural insensitivity are critical particularly with such a proposed diverse visiting group, as well as the potential for harm to the patient in the community outreach settings. Research has explored learning benefits to the student but empirical benefits in quality of care for the patients' have not been ascertained. ${ }^{23}$

To avoid paternalism in new international partnerships between developed and developing nations, early and open discussion is required to ensure the establishment of a structure that mutually beneficial for all parties. The goal of the GLP model is to foster a broader societal change underpinned by justice, where large-scale global inclusion becomes the social norm to eliminate health disparities.

\section{Encouragement versus dissuasion}

It is recognised that there is a delicate balance between supporting students to develop a meaningful interest in global health but also discouraging students from seeking global health placements for the opportunity to have an exotic experience. There is limited scientific literature discussing this issue, as it is most likely an emerging issue with the recent increase in global mobility making these opportunities more readily available. Initial research conducted by Raymond and Hall suggested that motivations for volunteer tourism included: $:^{28}$ wanting to feel that they contributed something; wanting to be distinguished from a tourist; wanting a sense of connection to the other; and a desire to experience real poverty. It was identified that these trends are problematic as it objectifies the other, and may become socioeconomic/poverty voyeurism and a commodification of people. It is suggested that best practice to avoid these trends includes: i) continued relationships; ii) longer-term engagement; iii) clarity around the purpose prior to travel; iv) deconstruction of categories of helpers and helped. ${ }^{11,26,27}$

Being mindful of this consideration, there are profound benefits to be gained from global experiences as has been discussed extensively in the literature, and students should be actively encouraged to be thoughtful in seeking such opportunities. It is important that the GLP model promotes student interest and facilitates the development of well-meaning students from idealistic helper to enterprising learner ${ }^{28}$ It is important to encourage and support genuine interest by students participating in these placements, as overseas opportunities may have positive outcomes in developing cultural understanding and global citizenship. ${ }^{26}$ Additionally the learning opportunities for both local and visiting students and academics and the establishment of global networks promote collaborations and the advancement of the UN SDGs into the future.

Correspondence: Jessica Lees, Faculty of Medicine, Dentistry, and health sciences, The University of Melbourne, Level 4, 766 Elizabeth Street, Victoria 3010, Australia. Tel.: +61.3.8344.9148 - Fax: +61.3.9347.8939.

E-mail: jessica.lees@unimelb.edu.au

Key words: Health Science education; university collaboration; global placements; cultural competency; interprofessional practice.

Acknowledgments: grateful thanks are extended to the Universitas 21 UNMDG Steering Committee for their continuous encouragement and support. We would also like to thank our colleagues at Kathmandu University for their support and we look forward to collaborating together on the pilot project of the Global Learning Partnership model.

Contributions: JL made substantial contributions to the body of work described in this manuscript, drafted the manuscript, approved final reviewed version; GW provided academic leadership for the body of work described in this manuscript, contributed to the conceptual design of the manuscript and reviewed the final version; FC made substantial contributions to the body of work described in this manuscript, made critical revisions of the manuscript and reviewed the final manuscript; AS made contributions to the body of work described in this manuscript, made critical revisions of the manuscript, and reviewed the final version; LR provided academic leadership for the body of work described in this manuscript, contributed to the conceptual design of the manuscript and reviewed the final version. Conflict of interest: the authors declare no potential conflict of interest.

Received for publication: 30 November 2015.

Accepted for publication: 21 January 2016.

CCopyright J. Lees et al., 2016

Licensee PAGEPress, Italy

Journal of Public Health Research 2016;5:658

doi:10.4081/jphr.2016.658

This work is licensed under a Creative Commons Attribution NonCommercial 4.0 License (CC BY-NC 4.0). 


\section{References}

1. Murray CJ., Vos T, Lozano R, et al. Disability-adjusted life years (DALYs) for 291 diseases and injuries in 21 regions, 1990-2010: a systematic analysis for the Global Burden of Disease Study 2010. Lancet 2012;380:2197-223.

2. Gore C. The post 2015 moment: towards sustainable development goals and a new global development paradigm. J Int Dev 2015;27:717-721.

3. Campinha-Bacote J. The process of cultural competence in the delivery of healthcare systems. J Transcult Nurs 2002;13:181-3.

4. Gill G, Babacan H. Developing a culturally responsiveness framework in health care systems: an Australian example. Divers Equity Health Care 2012;9:45-55.

5. Koprucu S. Raising global citizens: focus on cultural competency. School Business Affairs 2009;75:30-2.

6. Canadian Interprofessional Health Collaborative (CIHC). A national interprofessional competency framework. Vancouver: University of British Columbia; 2010.

7. Gilbert J. Interprofessional education for collaborative patient-centered practice. Nurs Leader 2005;18:32-8.

8. Gureckis TM, Markant DB. Self-directed learning: a cognitive and computational perspective. Perspect Psychol Sci 2012;7:464-81.

9. Spencer JA, Jordan RK. Learner centred approaches in medical education. Br Med J 1999;318:1280-3.

10. Savery JR. Overview of problem-based learning: definitions and distinction. Interdisciplin J Problem-based Learn 2006:11:9-20.

11. United Nations. A new global partnership: Eradicate poverty and transform economies through sustainable development. New York: United Nations Publications; 2013.

12. Creswell JW, Plano Clark VL. Designing and conducting mixed methods research, $2^{\text {nd }}$ ed. Thousand Oaks: Sage Publications; 2011

13. Galle J, Lingard L. A medical student's perspective of participation in an interprofessional education placement: an autoethnography. J Interprofessional Care 2010;24:722-33.

14. Morris J. Factors influencing the quality of student learning on practice placements. Learn Health Soc Care 2007;6:213-19.

15. World Health Organisation. Framework for action on interprofessional education and collaborative practice. Geneva: World Health Organisation Publications; 2010.

16. Dumholdt, E. Physical therapy research: principles and applications. 2nd ed. Philadelphia: WB Saunders Company; 2000.

17. Buchanan DR. Autonomy, paternalism, and justice: ethical priorities in public health. Am J Publ Health 2008;98:15-21.

18. Dacso M, Chandra A, Friedman H. Adopting an ethical approach to global health training: the evolution of the Botswana - University of Pennsylvania partnership. Acad Med 2013;88:1646-50.

19. Kerry VB, Ndung'u T, Walensky RP, et al. Managing the demand for global health education. PLoS Med 2011;8:e1001118.

20. Singer PA. Beyond Helsinki: a vision for global health ethics. Improving ethical behaviour depends on strengthening capacity. $\mathrm{Br}$ Med J 2001;31:747-8.

21. Benetar SR, Daar AS, Singer PA. Global health ethics: the rationale for mutual caring. Int Affairs 2003;79:107-38.

22. Gasper D. Ethics and the conduct of international development aid: charity and obligation. Forum Dev Stud 1999;1:23-57.

23. Bhar SB. Ethical coherency when medical students work abroad. Lancet 2008;372:1133-4.

24. Haq C, Lukolyo H, Graber ME, et al. Clinical case: with so much need, where do I serve? Am Med Assoc J Ethics 2010;12:149-58.

25. Ramsey AH, Haq C, Gjerde CL, Rothenberg D. Career influence of an international health experience during medical school. Fam Med 2004;36:412-6.

26. Raymond EM, Hall CM. The development of cross-cultural (Mis) understanding through volunteer tourism. J Sust Tourism 2008;16:530-43.

27. Cassidy T. The global education initiative (GEI) model of effective partnership initiative for education. Geneva: World Economic Forum; 2007.

28. Wickford J, Rosberg S. From idealistic helper to enterprising learner: Critical reflections on personal development through experiences from Afghanistan. Physiother Theory Pract 2012;28:283-91. 